\title{
Repeated recurrence of thoracic spine stenosis following decompression alone for ossification of the ligamentum flavum: case report
}

\author{
Abhijeet S. Barath, MBBS, Osmond C. Wu, MD, Mohit Patel, MD, and Manish K. Kasliwal, MD, MCh \\ Department of Neurological Surgery, University Hospitals Cleveland Medical Center, Cleveland, Ohio \\ Ossification of the ligamentum flavum (OLF) is a well-recognized but rare cause of thoracic myelopathy. Its subtle and \\ variable clinical presentation often makes the diagnosis challenging. The treatment of symptomatic OLF requires surgical \\ intervention, with the most common surgical procedure being a posterior decompression with or without instrumentation. \\ Recurrence of ossification and stenosis after surgery is rare and usually occurs at the same intervertebral level. Multiple \\ recurrences of ossification and stenosis are exceptionally rare. The authors report the case of OLF in a 60-year-old \\ man who experienced recurrence of ossification and stenosis twice after posterior decompression surgeries alone. The \\ patient was ultimately treated with revision decompression and instrumented fusion. The authors also present a pertinent \\ review of the literature.
}

https://thejns.org/doi/abs/10.3171/2018.8.SPINE18517

KEYWORDS ossification of the ligamentum flavum; OLF; recurrence; thoracic spine

$\mathrm{O}$ SSIFICATION of the ligamentum flavum (OLF) is an important cause of thoracic myelopathy and usually presents as compressive myelopathy requiring surgical decompression. ${ }^{1,11,16}$ The majority of cases of OLF have been reported in the East Asian population with a relatively rare occurrence in the western population., $1,5,12,16$ The lower third of the thoracic spine, particularly T10-11, is most commonly affected, likely due to increased biomechanical stress in the region., ${ }^{2,59-11,16}$ While often resulting in progressive thoracic myelopathy, it can also present as an incidental finding, back pain, acute paraplegia after minor trauma, or spontaneous intracranial hypotension. . $^{1,3,10,11,13,14,16}$ Once symptomatic, surgical decompression remains the treatment of choice..$^{1,10,16}$ Although rare, recurrence of ossification and stenosis has been reported in the literature after laminectomy alone, often at the same intervertebral level.,7,11,16 We present the rare case of thoracic OLF in a 60-year-old man with 2 recurrences of ossification and stenosis after posterior decompression surgeries alone that was ultimately treated with a decom- pression and instrumented fusion with a successful clinical outcome.

\section{Case Report \\ History and Presentation}

A 60 -year-old man had presented 5 years previously with numbness and tingling of his feet as well as mild gait imbalance. At that time, MRI of the thoracic spine without gadolinium demonstrated stenosis at T2-3, T6-7, and T7-8 (Fig. 1A-C). CT scanning of the thoracic spine without contrast revealed ossification of the ligamentum flavum from T1-9 and T11-12, with the worst levels as noted above (Fig. 1D-F). The patient underwent T2, T6, $\mathrm{T} 7$, and $\mathrm{T} 8$ laminectomies and excision of the ossified ligamentum flavum with medical facetectomies but preservation of facet joints. Postoperative CT scans showed good decompression at the operated levels (Fig. 2). Four years after the initial surgery, the patient presented with similar complaints, and CT scans demonstrated recurrence of os- 


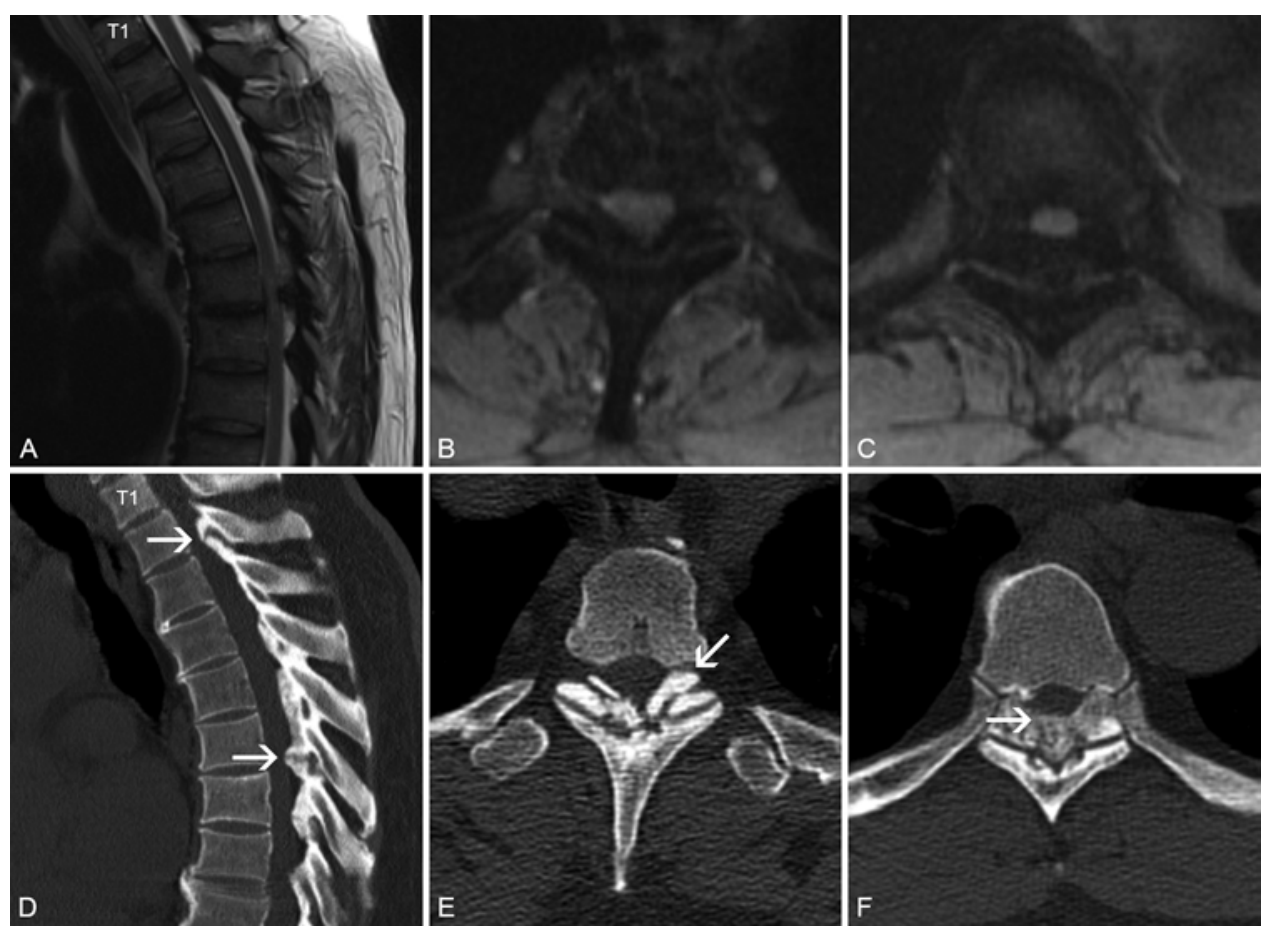

FIG. 1. Sagittal T2-weighted MR image demonstrating stenosis of the thoracic spinal cord (A) with corresponding axial images at T2-3 (B) and T6-7 (C). Sagittal CT image demonstrating OLF of the thoracic spine (D) with corresponding axial images at T2-3

(E) and T6-7 (F). Arrows indicate areas of OLF.

sification at T2-3 and T6-7 with associated canal stenosis (Fig. 3). He underwent repeat T3, T6, and T7 laminectomies with decompression and re-excision of ossification without any facetectomies by another surgeon.

The patient presented again nearly 1 year later with similar symptoms and signs of myelopathy. CT scans demonstrated recurrence of ossification at T6-7 (Fig. 4D-F). MRI confirmed severe canal stenosis and spinal cord compression at the level of T6-7 with bony ingrowth medial to the pedicles and involvement of the facet joints (Fig. 4A-C).

\section{Operation}

A repeat posterior decompression was performed. Hypertrophic bony overgrowth was encountered at the T6-7 level, involving the pedicle and facets. This overgrowth was removed using a high-speed drill, Kerrison rongeurs, and curettes. An intraoperative durotomy occurred because the dura was completely eroded and thinned out at the site of compression, which was repaired by a dural patch and glue. Posterior segmental instrumentation was placed from T5 to T8 with posterolateral arthrodesis.

\section{Postoperative Course}

At the 1-year follow-up, the patient remained neurologically intact.

\section{Discussion}

OLF remains a well-recognized cause of myelopathy
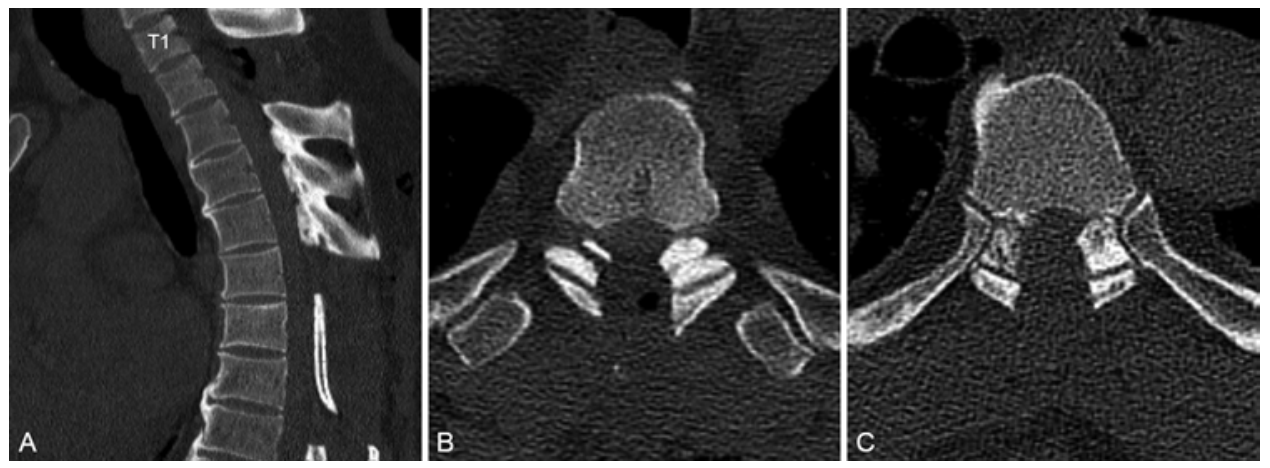

FIG. 2. Postoperative sagittal CT image demonstrating resection of the ossified ligamentum flavum (A) with corresponding axial images at T2-3 (B) and T6-7 (C). 

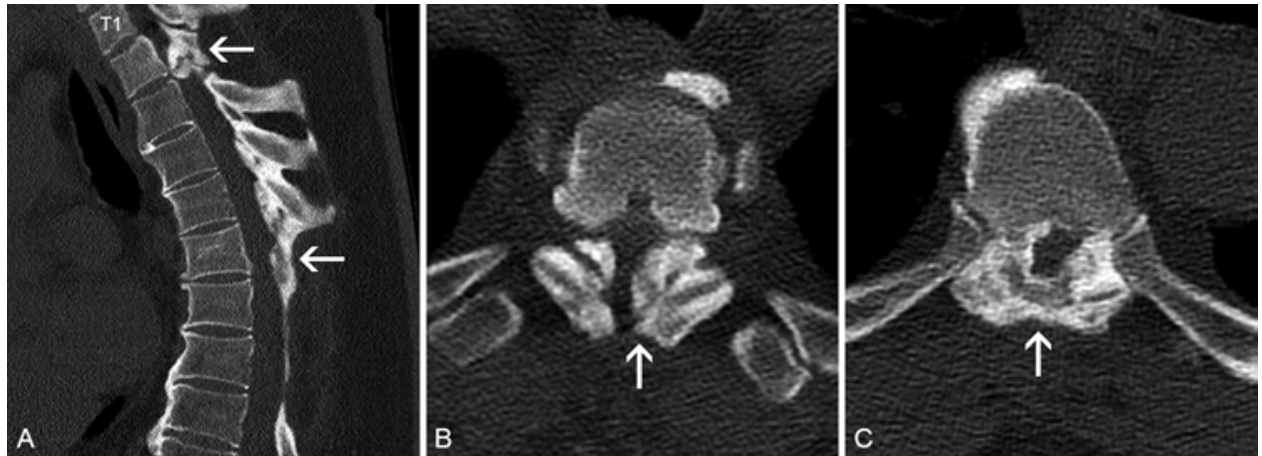

FIG. 3. Sagittal CT image obtained 4 years after the initial surgery, demonstrating recurrence of ossification at T2-3 and T6-7 (A) Corresponding axial images at T2-3 (B) and T6-7 (C). Arrows indicate recurrence of ossification.

often affecting the thoracic spine, with a higher incidence reported in the East Asian population, particularly in Japan. The pathogenesis of OLF remains poorly understood and is likely multifactorial, involving mechanical, metabolic, genetic factors, increased tendency for heterotopic ossification, endemic fluorosis, and increased biomechanical stress in the lower thoracic region. ${ }^{11,15}$ While the lower thoracic spine is the most common location, OLF has also been reported in the cervical spine. Most cases of OLF in the cervical spine are associated with ossification of the posterior longitudinal ligament. .,10

When symptomatic, OLF is best treated surgically with various options such as laminotomy, laminectomy, and laminoplasty with or without instrumentation and fusion, and with or without removal of the ossified dura. ${ }^{1,14}$ Favorable surgical prognostic factors include a short duration between the onset of symptoms and surgical intervention, presence of mild myelopathy, and OLF at a single level with unilateral disease..$^{1-3,8}$ Meanwhile, poor prognostic factors include presence of severe myelopathy, intramedullary cord signal changes, degree of anteroposterior compression, and presence of the OLF in the midthoracic spine..$^{8,17}$

While recurrence of ossification after surgery has been previously described, it is very rare and the risk factors for recurrence and progression following previous decompressive surgeries remain poorly understood. Considering the possible role of biomechanical stress, the option of instrumented fusion may be entertained at the time of first recurrence following decompression alone so as to potentially avoid multiple recurrences, as was seen in the present case. Review of the images in our case shows the
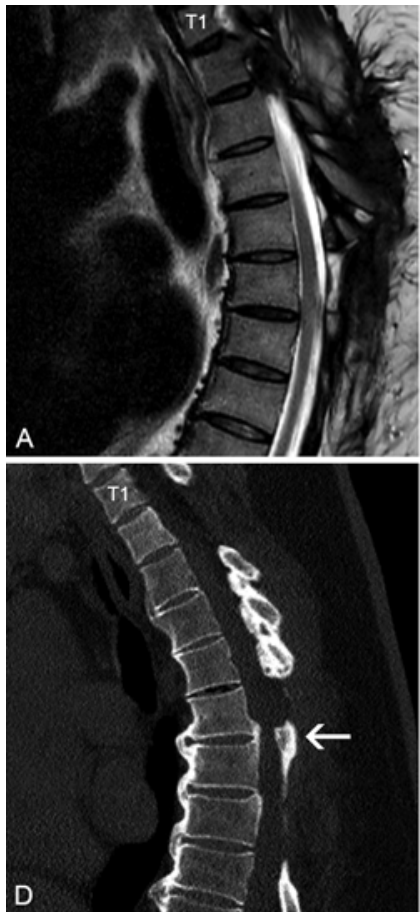
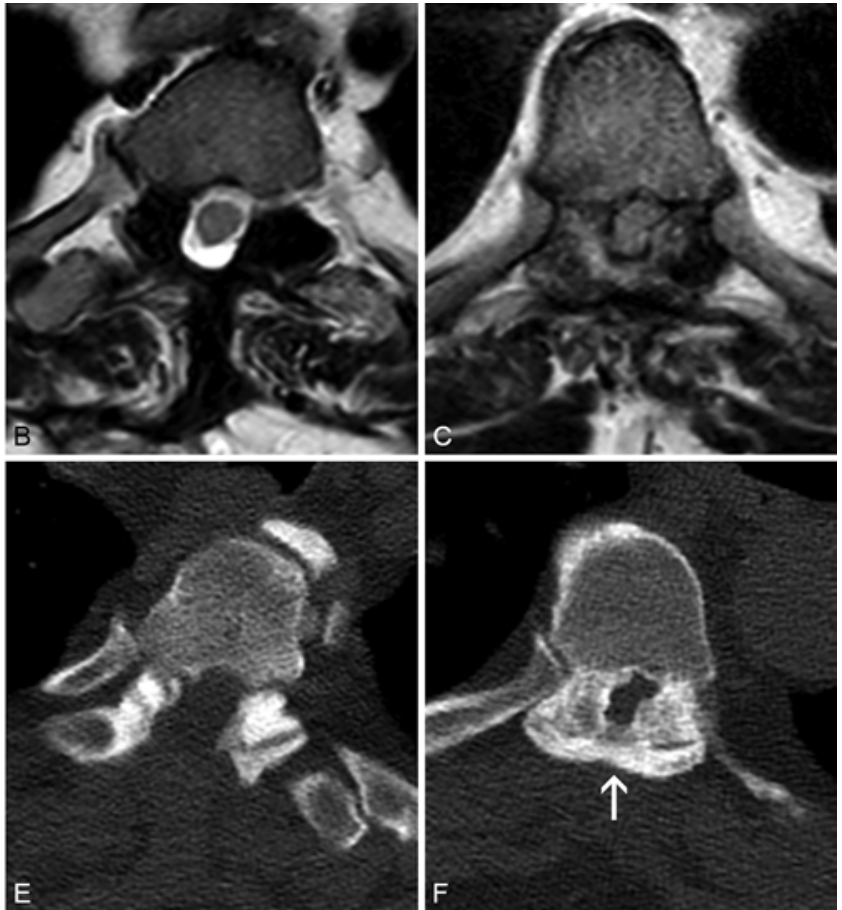

FIG. 4. Sagittal T2-weighted MR image obtained 1 year after the second surgery, demonstrating recurrence of stenosis at T6-7

(A). Corresponding axial images at T2-3 (B) and T6-7 (C). Sagittal CT image demonstrating recurrence of ossification at T6-7

(D). Corresponding axial images at T2-3 (E) and T6-7 (F). Arrows indicate recurrence of ossification. 
TABLE 1. Cases of recurrent ossification after OLF decompression in the literature

\begin{tabular}{|c|c|c|c|c|c|c|c|c|c|}
\hline $\begin{array}{c}\text { Authors \& } \\
\text { Year }\end{array}$ & $\begin{array}{l}\text { Age } \\
\text { (yrs), } \\
\text { Sex }\end{array}$ & $\begin{array}{c}\text { Level of } \\
\text { OLF }\end{array}$ & 1st Procedure & $\begin{array}{c}\text { Level of 1st } \\
\text { Recur }\end{array}$ & $\begin{array}{l}\text { Latency } \\
\text { to } 1 \text { st } \\
\text { Recur } \\
\text { (mos) }\end{array}$ & 2nd Procedure & $\begin{array}{l}\text { Level } \\
\text { of } 2 n d \\
\text { Recur }\end{array}$ & $\begin{array}{l}\text { Latency } \\
\text { to } 2 \text { nd } \\
\text { Recur } \\
\text { (mos) }\end{array}$ & 3rd Procedure \\
\hline \multirow[t]{4}{*}{$\begin{array}{c}\text { Yonenobu } \\
\text { et al., } \\
1987\end{array}$} & NS & NS & Laminectomies & $\begin{array}{l}\text { Progression } \\
\text { of lower } \\
\text { segment }\end{array}$ & 84 & $\begin{array}{l}\text { Anterior decompression } \\
\text { w/ corpectomy \& strut } \\
\text { graft }\end{array}$ & NA & NA & NA \\
\hline & NS & NS & Laminectomies & NS & 66 & Laminectomies & NA & NA & NA \\
\hline & NS & NS & Laminectomies & $\begin{array}{l}\text { Progression } \\
\text { of lower } \\
\text { segment }\end{array}$ & 60 & $\begin{array}{l}\text { Anterior decompression } \\
\text { w/ corpectomy \& strut } \\
\text { graft }\end{array}$ & NA & NA & NA \\
\hline & NS & NS & $\begin{array}{l}\text { Anterior decompres- } \\
\text { sion w/ corpec- } \\
\text { tomy \& strut graft }\end{array}$ & $\begin{array}{l}\text { Progression } \\
\text { of upper } \\
\text { segment }\end{array}$ & 86 & Laminectomies & NA & NA & NA \\
\hline \multirow{2}{*}{$\begin{array}{l}\text { Okada et } \\
\quad \text { al., } 1991\end{array}$} & NS & NS & Laminectomies & Local recur & NS & Laminectomies & NA & NA & NA \\
\hline & NS & NS & Laminectomies & Local recur & NS & Laminectomies & NA & NA & NA \\
\hline $\begin{array}{l}\text { Ando et } \\
\text { al., } 2014\end{array}$ & $36, \mathrm{M}$ & $\begin{array}{l}\text { T3-4, } \\
\text { T4-5 }\end{array}$ & $\begin{array}{l}\text { T3, T4, \& T5 laminec- } \\
\text { tomies, L2-4 } \\
\text { instrumented } \\
\text { fusion }\end{array}$ & $\begin{array}{c}T 1-3 \& \\
T 7-11\end{array}$ & 70 & $\begin{array}{l}\text { C3-7 laminoplasty, } \\
\text { T1-11 laminectomies, } \\
\text { T6-9 instrumented } \\
\text { fusion }\end{array}$ & T10-11 & 11 & $\begin{array}{l}\text { Resection of ossifica- } \\
\text { tion, T6-L4 instru- } \\
\text { mented fusion }\end{array}$ \\
\hline \multirow[t]{2}{*}{$\begin{array}{c}\text { Kanno } \\
\text { et al., } \\
2018\end{array}$} & $47, \mathrm{~F}$ & $\begin{array}{l}\text { T9-10 to } \\
\text { T12-L1 }\end{array}$ & $\begin{array}{l}\text { T9, T10, T11, T12, \& } \\
\text { L1 laminectomies } \\
\text { \& resection of } \\
\text { OLF }\end{array}$ & $\begin{array}{l}\mathrm{T} 9-10 \text { to } \\
\mathrm{T} 12-\mathrm{L} 1\end{array}$ & 132 & $\begin{array}{l}\text { Resection of ossification } \\
\text { at T9-10, T10-11, \& } \\
\text { T8-L2 instrumented } \\
\text { fusion }\end{array}$ & NA & NA & NA \\
\hline & $54, \mathrm{M}$ & T10-11 & $\begin{array}{l}\text { T10, T11 laminecto- } \\
\text { mies \& resection } \\
\text { of OLF }\end{array}$ & T10-11 & 48 & $\begin{array}{l}\text { Resection of ossifica- } \\
\text { tion at T10-11, T9-L1 } \\
\text { instrumented fusion }\end{array}$ & NA & NA & NA \\
\hline $\begin{array}{r}\text { Present } \\
\text { case }\end{array}$ & $55, \mathrm{M}$ & $\begin{array}{l}\text { T2-3, } \\
\text { T6-7, } \\
\text { T7-8 }\end{array}$ & $\begin{array}{l}\text { T2, T6, T7, \& T8 } \\
\text { laminectomies \& } \\
\text { resection of OLF }\end{array}$ & T2-3, T6-7 & 47 & $\begin{array}{l}\text { T3, T6, \& T7 laminecto- } \\
\text { mies \& resection of } \\
\text { ossification }\end{array}$ & T6-7 & 11 & $\begin{array}{l}\text { T6 transpedicular de- } \\
\text { compression, T5-8 } \\
\text { instrumented fusion }\end{array}$ \\
\hline
\end{tabular}

NA = not applicable; NS = not specified; recur = recurrence.

presence of anterior ankylosis at T3-4 where there was no OLF at presentation or recurrence of ossification after decompression. This further lends support to the observation that fusion surgery or presence of autofusion/ankylosis may prevent development or regrowth of ossification. No recurrence of ossification at the fused levels has been reported in the literature following a fusion. ${ }^{5,7,16}$ This is also supported by the fact that the lower thoracic spine, where there is increased biomechanical stress, is the most common site of OLF. Table 1 summarizes the characteristics of cases described in the literature to date.

\section{Conclusions}

We described a rare case of OLF with 2 recurrences of ossification and stenosis after posterior decompression surgeries alone. The OLF was then successfully treated with decompression with instrumented fusion the third time. While it is difficult to ascertain the best treatment modality for recurrent OLF given the lack of literature, instrumented fusion should be considered as an option at the time of first recurrence to alleviate persistent pathological biomechanical stress and likely obviate further progression and recurrence of ossification in light of no reported cases of recurrence after instrumented fusion. Since the recurrence of stenosis from regrowth of ossification may not be apparent until after a few years, as occurred after the first decompression in the present study, the lack of long-term follow-up after the fusion remains a limitation of this study. We acknowledge that long-term follow-up will be needed to fully evaluate the success of fusion in such patients.

\section{References}

1. Ahn DK, Lee S, Moon SH, Boo KH, Chang BK, Lee JI: Ossification of the ligamentum flavum. Asian Spine J 8:89-96, 2014

2. Aizawa T, Sato T, Sasaki H, Kusakabe T, Morozumi N, Kokubun S: Thoracic myelopathy caused by ossification of the ligamentum flavum: clinical features and surgical results in the Japanese population. J Neurosurg Spine 5:514-519, 2006

3. Aizawa T, Sato T, Sasaki H, Matsumoto F, Morozumi N, Kusakabe T, et al: Results of surgical treatment for thoracic myelopathy: minimum 2-year follow-up study in 132 patients. J Neurosurg Spine 7:13-20, 2007

4. Ando K, Imagama S, Ito Z, Kobayashi K, Ukai J, Muramoto A, et al: Progressive relapse of ligamentum flavum ossification following decompressive surgery. Asian Spine J 8:835839, 2014

5. Guo JJ, Luk KD, Karppinen J, Yang H, Cheung KM: Preva- 
lence, distribution, and morphology of ossification of the ligamentum flavum: a population study of one thousand seven hundred thirty-six magnetic resonance imaging scans. Spine (Phila Pa 1976) 35:51-56, 2010

6. Inoue H, Seichi A, Kimura A, Endo T, Hoshino Y: Multiplelevel ossification of the ligamentum flavum in the cervical spine combined with calcification of the cervical ligamentum flavum and posterior atlanto-axial membrane. Eur Spine J 22 (Suppl 3):S416-S420, 2013

7. Kanno H, Takahashi T, Aizawa T, Hashimoto K, Itoi E, Ozawa H: Recurrence of ossification of ligamentum flavum at the same intervertebral level in the thoracic spine: a report of two cases and review of the literature. Eur Spine J 27 (Suppl 3):359-367, 2018

8. Kuh SU, Kim YS, Cho YE, Jin BH, Kim KS, Yoon YS, et al: Contributing factors affecting the prognosis surgical outcome for thoracic OLF. Eur Spine J 15:485-491, 2006

9. Li B, Qiu G, Guo S, Li W, Li Y, Peng H, et al: Dural ossification associated with ossification of ligamentum flavum in the thoracic spine: a retrospective analysis. BMJ Open 6:e013887, 2016

10. Miyasaka K, Kaneda K, Sato S, Iwasaki Y, Abe S, Takei H, et al: Myelopathy due to ossification or calcification of the ligamentum flavum: radiologic and histologic evaluations. AJNR Am J Neuroradiol 4:629-632, 1983

11. Okada K, Oka S, Tohge K, Ono K, Yonenobu K, Hosoya T: Thoracic myelopathy caused by ossification of the ligamentum flavum. Clinicopathologic study and surgical treatment. Spine (Phila Pa 1976) 16:280-287, 1991

12. Shiguematsu FY, de Souza EC, Zimmermann AF, Castro GR, Pereira IA, Neves FS: Thoracic myelopathy due to calcification of the ligamentum flavum with hyperproteinorachia and responsive to steroid therapy: case report. Rev Bras Reumatol 52:438-446, 2012

13. Turel MK, Kerolus MG, O’Toole JE: Ossified ligamentum flavum of the thoracic spine presenting as spontaneous intracranial hypotension: case report. J Neurosurg Spine 28:401-405, 2018

14. Wang K, Chen X: Thoracic cord compression caused by contiguous multilevel ossification of ligamentum flavum in Chinese patients. Chin J Traumatol 10:213-217, 2007

15. Wang W, Kong L, Zhao H, Dong R, Li J, Jia Z, et al: Thoracic ossification of ligamentum flavum caused by skeletal fluorosis. Eur Spine J 16:1119-1128, 2007

16. Yonenobu K, Ebara S, Fujiwara K, Yamashita K, Ono K, Yamamoto T, et al: Thoracic myelopathy secondary to ossification of the spinal ligament. J Neurosurg 66:511-518, 1987

17. Yu S, Wu D, Li F, Hou T: Surgical results and prognostic factors for thoracic myelopathy caused by ossification of ligamentum flavum: posterior surgery by laminectomy. Acta Neurochir (Wien) 155:1169-1177, 2013

\section{Disclosures}

The authors report no conflict of interest concerning the materials or methods used in this study or the findings specified in this paper.

\section{Author Contributions}

Conception and design: Kasliwal. Drafting the article: Wu, Barath, Patel. Critically revising the article: Wu, Patel, Kasliwal. Reviewed submitted version of manuscript: Wu, Kasliwal. Approved the final version of the manuscript on behalf of all authors: Wu. Administrative/technical/material support: $\mathrm{Wu}$.

\section{Correspondence}

Osmond C. Wu: University Hospitals Cleveland Medical Center, Cleveland, OH. osmond.wu@uhhospitals.org. 